\title{
A PRODUÇÃO ACADEMICA EM POLÍTICAS EDUCACIONAIS PARA FORMAÇÃO DE PROFESSORES DA EDUCAÇÃO INFANTIL (2005-2010)
}

\author{
Andressa Cerqueira Gonçalves ${ }^{1}$; Fani Quitéria Nascimento Rehem² ${ }^{2}$. \\ 1. Bolsista PIBIC/FAPESB, Graduanda em Licenciatura em Pedagogia, Universidade Estadual de Feira de Santana, e-mail: \\ andressacg.ag@gmail.com \\ 2. Orientadora, Departamento de Educação, Universidade Estadual de Feira de Santana, e-mail: \\ fanirehem@gmail.com
}

PALAVRAS-CHAVE: Formação de Professor; Educação Infantil; Produção Acadêmica

\section{INTRODUÇÃO}

A pesquisa - A Produção Acadêmica em Políticas Educacionais para Formação de Professores na Educação Infantil no Brasil (2005-2010) - oriunda da bolsa de Iniciação Científica (IC), PIBIC/FAPESB, edital 2017/2017 é parte do projeto intitulado "Questões Epistemológicas e Metodológicas da Produção Acadêmica em Políticas Educacionais no Brasil (2000-2010)", que utiliza como base um banco de dados com 1.283 teses e dissertações, a partir do banco de dados da Coordenação de Aperfeiçoamento de Pessoal de Nível Superior (CAPES), cujo critério de seleção foram as produções das Instituições de Ensino Superior que tiveram no igual ou superior a 5 no exame trienal da CAPES em 2010, tem como objetivo geral analisar as características das teses e dissertações produzidas no período de 2000 a 2005 nos programas de pós-graduação em educação e identificar as principais tendências dessa produção, em relação às perspectivas de constituição do campo de estudo em políticas educacionais para Formação de Professores na Educação Infantil.

Considera-se aqui, que a Educação Infantil, por muito tempo, fora marginalizada, considerando a própria construção do campo de atuação destas professoras, apresentando, portanto, muitas fragilidades, além da invisibilidade perante os órgãos públicos. É a partir da promulgação da Lei de Diretrizes e Bases da Educação Nacional - LDB 9394/96, de 20 de dezembro de 1996 que a educação infantil passa a compor a Educação Básica, como primeira etapa desta educação.

Desse modo, evidenciamos a importância de um estudo crítico sobre a formação de professores da educação infantil, considerando também a pouca produção no campo das políticas educacionais voltadas à infância, conforme aponta Rehem (2013) de que embora haja um crescimento nas pesquisas sobre criança e sua educação, a ênfase se dá nas análises da prática, do cotidiano em que se destacam as atividades pedagógicas sobre o contexto político.

\section{MATERIAL E MÉTODOS OU METODOLOGIA (ou equivalente)}

Em vista do exposto, opta-se pela pesquisa em "Estado da Arte" ou "estado do conhecimento" que diz respeito a uma categoria de pesquisa "usual na literatura científica americana" (BRANDÃO, 1986, p.7 apud ROMANOWSKI \&ENS, 2006) e recente no Brasil, que tem como objetivo central mapear e discutir o que se tem produzido sobre determinado tema. A abordagem é qualitativa e conta com elementos quantitativos, o que implica no crescimento do assunto específico conduzido pelas peculiaridades do pesquisador, incluindo suas definições políticas, palavras de Ludke e André (1986).

Os procedimentos adotados foram delineados a partir dos objetivos traçados, por isso a referida pesquisa envolveu dois momentos: no primeiro realizamos o mapeamento a partir dos seguintes descritores: Formação de Professores, Educação Infantil, Creche e Pré-Escola, identificando aspectos como: autor, orientador, título, palavras-chave, linha de pesquisa, instituição e localização geográfica a partir do Banco de Dados do CEDE. No segundo 
momento, analisamos as tendências dessas produções a partir da análise dos resumos apresentados e das questões presentes na ficha descritiva e analítica.

\section{RESULTADOS}

As produções acadêmicas referentes às Políticas Educacionais para Formação de Professores da Educação Infantil no Brasil (2005-2010) identificadas e organizadas através dos seguintes descritores: Formação de Professores, Educação Infantil, creche e pré-escola, revelou a existência de 7 produções de pós-graduação (P) distribuídas nos anos de 2005 a 2010 no Banco de Dados do CEDE. Sendo 2 P em 2005, 2 P em 2007 e 3 P em 2009.

Em conformidade ao exposto na metodologia deste trabalho, as 1.283 produções de pósgraduação organizadas pelo projeto maior foram organizadas em 9 eixos: Eixo 1 - Organização da educação, planejamento da educação, administração da educação, gestão da educação; Eixo 2 - Avaliação em larga escala e avaliação institucional; Eixo 3 - Qualidade da educação, qualidade de ensino; Eixo 4 - Reformas educacionais, neoliberalismo na educação, terceiro setor e organizações sociais na educação, Estado e reformas educacionais, análise e avaliação de políticas educacionais; Eixo 5 - Políticas de formação de professores e carreira docente; Eixo 6 - Financiamento da educação, controle social do financiamento da educação; Eixo 7 Abordagens teórico-metodológicas em pesquisas sobre políticas educacionais; Eixo 8 - Análise e avaliação de Programas e projetos no campo educacional; Eixo 9 - Políticas inclusivas, no entanto, as produções sobre a área em questão concentraram-se todas no eixo 5.

Conforme o achado, se faz necessário traçar um comparativo com relação às temáticas sobre Políticas Educacionais para Educação Infantil, Políticas Educacionais para Formação de Professores e Carreira Docente e Políticas Educacionais para Formação de Professores na Educação Infantil.

Portanto foram encontradas 72 produções com foco nas Políticas Educacionais para Educação Infantil (MONTEIRO, 2017), 118 produções sobre Formação de Professores e Carreira Docente (PENNA \& BELLO, 2016) e 7 produções sobre Políticas Educacionais para Formação de Professores na Educação Infantil. Percebe-se que o recorte temático do presente estudo é irrisório, demonstrando a fragilidade discursiva referente ao campo de políticas para formação de professores da educação infantil.

A grande quantidade de produções sobre formação de professores testifica a preocupação dos mestres e doutores em abordar a temática. Romanowski (2013) aponta que,

[..] a pesquisa da/na formação dos professores, realizada nos cursos universitários, e mesmo no curso normal secundário, somente assume relevância a partir da década de 1980 . Nesse período, os debates em torno da pesquisa em formação de professores passaram a ocorrer em simpósios, reuniões, artigos, investigações, teses e dissertações (ROMANOWSKI, 2013, p.480).

A ampliação e relevância a partir da referida década teve como estímulo a crítica aos modelos técnicos vigentes até o final dos anos 1970, segundo Maia e Hobold (2014, p.5) em que "os currículos de formação de professores eram norteados pela racionalidade técnica, marcados fortemente pelo paradigma positivista, e o professor deveria resolver os problemas da prática por meio da aplicação de teorias e técnicas científicas". Acrescido a estes fatores, Penna e Bello (2016) revelam que o crescimento da produção também se deve ao fato de que houve um aumento dos programas de pós-graduação em educação assim como a discussão sobre a qualidade do ensino, que, nas palavras das autoras tem o professor como peça chave para a melhoria do processo.

É observável que as pesquisas tendem para formação de professores (inicial e continuada) e as análises dos aspectos da carreira e trabalho docente. Como posto, a LDB tem bastante relevância já que a partir da referida lei que há maiores exigências para os profissionais 
de educação. Lamentavelmente, as circunstâncias tenderam a precarização desse processo formativo, como exposto, mas deveria proporcionar justamente o oposto.

É importante destacar o crescimento nas produções referentes a Educação Infantil com os mais diversos enfoques a partir da década de 1990, "o crescimento da Educação Infantil como área de estudo tem ocorrido sobretudo, nos sistemas públicos de educação e a presença desta temática na política nacional, esteve acompanhada de um aprofundamento e da ampliação do conhecimento na área" (STRENZEL, 2000). Todavia, no que concerne à agenda política, a quantidade diminui consideravelmente e ao se tratar da formação dos docentes desta etapa de ensino a situação é ainda mais crítica.

Esses resultados comungam com o estudo anterior ${ }^{1}$, mas ao confrontar os resultados anteriores, verifica-se que a partir do ano de 2005, as produções aumentam significativamente, com exceção do campo de estudo abordado neste relatório. No período entre 2000 e 2005 foram localizadas $35 \mathrm{P}$ referentes a Educação Infantil com os mais diferentes enfoques e $86 \mathrm{P}$ a respeito da Formação de Professores e Carreira Docente.

Com relação a distinção das produções do presente estudo, observa-se que o número de dissertações (5) é superior a quantidade de teses (2), com as produções concentrando-se mais nos cursos de mestrado. Strenzel (2000), ao pesquisar sobre a produção científica sobre educação infantil no Brasil nos programas de pós-graduação em educação, em uma análise com base no CD ROM da Associação Nacional de Pós Graduação e Pesquisa em Educação (Anped) também verificou essa prevalência, afirmando que "no que diz respeito às teses de doutorado, este crescimento é mais recente", outro fator relevante é o maior número de programas de pós graduação para estudantes de mestrado.

Com relação às Instituições de Ensino Superior (IES), encontram-se nas seguintes Universidades: Universidade Federal do Rio Grande Do Sul (UFGRS), Universidade Estadual de Campinas (UNICAMP) Universidade Fluminense Federal (UFF), Universidade Estadual Paulista Júlio de Mesquita Filho - campus Marília (UNESP-MAR) e Universidade Federal de Minas Gerais (UFMG). Em termo de localização geográfica, estas IES estão nas regiões Sul e Sudeste.

Tais questões nos fazem refletir que as discussões acadêmicas nestas localidades regionais há concentração em algumas regiões e escassez em outras. Bello, Jacomini e Minhoto (2016) indicam que,

[...] é uma situação preocupante, pois[...] indica ampliação da histórica desigualdade de produção de conhecimento entre as regiões do país, reproduzindo o fenômeno em que justamente as regiões que mais necessitam de analises e dados sobre suas condições são as que menos aparecem como objeto de pesquisa (BELLO, JACOMINI \& MINHOTO, 2016, p.87).

Neste caso específico, não há produções nas regiões Norte, Nordeste e Centro-Oeste, o que, segundo as autoras é relevante tendo em vista a concentração dos cursos de pós-graduação (mestrado e doutorado) nas regiões Sul e Sudeste na área de Educação e os escores estabelecidos pelo critério da pesquisa anterior que teve como corte os programas de pósgraduação em educação com nota igual ou superior a 5. Fator este que pode ter influenciado, como revela a análise dos dados, o não aparecimento das regiões Norte e Nordeste na presente análise, isto não significa dizer que essas regiões não discutem sobre a temática em questão, bem como a qualidade discursiva dos seus cursos de pós-graduação.

Os títulos das teses e dissertações dizem muito sobre a temática e é um elemento em destaque para as pesquisas que têm como metodologia o estado da arte, conforme Ferreira

\footnotetext{
${ }^{1}$ Plano de trabalho intitulado por “A produção acadêmica em políticas educacionais para Formação de Professores na Educação Infantil no Brasil 2000-2005”, aprovado pela Fundação de Amparo à Pesquisa do Estado da Bahia (FAPESB) edital 2016/2017.
} 
(2002, p.261) "Normalmente, eles anunciam a informação principal do trabalho ou indicam elementos que caracterizam o seu conteúdo".

Ainda segundo a autora, os títulos diferem bastante, podendo ser curtos, longos, densos, subjetivos, sendo concluídos com diversas pontuações. Neste estudo as titulações foram objetivas e apenas uma dissertação é questionamento, ou seja, há interrogação ao final. Posteriormente, observa-se que as características dos resumos não são padronizadas e que negligenciam informações importantes, por isso o acesso a obra foi necessário nesse momento.

No que tange as escolhas teóricas (base teórica e/ou autores), por exemplo, não foi apresentado na maioria dos trabalhos o que inviabiliza ao leitor a identificar o lugar de fala do autor, sendo necessário ter acesso a obra.

\section{CONSIDERAÇÕES FINAIS}

Através da catalogação das produções acadêmicas e análise dos respectivos resumos e das questões presentes na ficha descritiva e analítica, percebe-se a discrepância entre produção com foco na temática políticas educacionais para Formação de Professores na Educação Infantil (7P), Formação de Professores (118P) e Educação Infantil (72P). As regiões de localização das produções, teses e dissertações, são Sul (1) e Sudeste (4), nas respectivas instituições: UFGRS, UNICAMP, UFF, UNESP-MAR, e UFMG. Portanto, percebe-se, com os nossos achados a necessidade de estudos que problematizem a política de formação de professores, inquirindo seus objetos, suas concepções de formação e de educação infantil, indicando com isso as lacunas neste campo de estudo.

\section{REFERÊNCIAS}

BELLO, I. M.; JACOMINI, M. A. MINHOTO, M. A. P. Produção acadêmica em política educacional no Brasil: análise de teses e dissertações (2000-2010). In: _ SILVA, Antônia Almeida; JACOMINI, Márcia Aparecida, organizadoras. Pesquisa em políticas

educacionais: características e tendências. - Feria de Santana: UEFS Editora, 2016. Cap. 2, p.63-92.

FERREIRA, N. S. de A. As pesquisas denominadas "estado da arte". Educ. Soc. [online]. 2002, vol.23, n.79, pp.257-272. ISSN 0101-7330. http://dx.doi.org/10.1590/S010173302002000300013.

LUDKE, M.; ANDRÉ, M. Pesquisa em educação: abordagens qualitativas. São Paulo: E.P.U. 1986.

PENNA, M. G. O, BELLO, I. M. Políticas de formação de professores e carreira docente no Brasil: A produção do conhecimento e o posicionamento epistemológico dos pesquisadores na área. In: _ SILVA, A. A.; JACOMINI, M. A., organizadoras. Pesquisa em políticas educacionais: características e tendências. Feria de Santana: UEFS Editora, 2016. Cap. 5 , p.155-176

ROMANOWSKI, J. P.; ENS, Romilda Teodora. As pesquisas denominadas do tipo

"Estado da Arte" em educação. In: Diálogo Educ., Curitiba, v. 6, n.19, p.37-50, set./dez. 2006.

ROMANOWSKI, J. P. Tendências da pesquisa em formação de professores. In: Atos de pesquisa em educação - PPE/ME. ISSN 1809-0354 v.8, n.2, p.479-499, mai.ago. 2013. DOI http://dx.doi.org/10.7867/1809-0354.2013v8n2p479-499.

STRENZEL, G. R. A Produção Científica sobre Educação Infantil no Brasil nos Programas de Pós Graduação em Educação. - REUNIÃ̃O ANUAL DA ANPEd, 2000 anped.org.br. http://www.anped.org.br/sites/default/files/gt_07_06.pdf. 